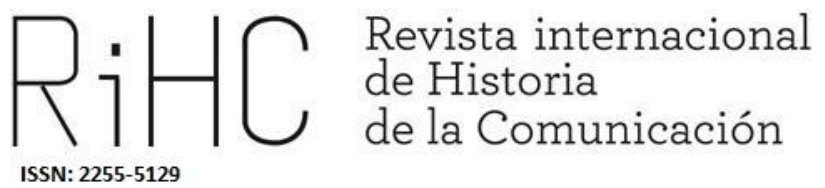

\title{
EL PRINCIPIO DEL FIN DE ADOLFO SUÁREZ. LA PRENSA Y LA TELEVISIÓN ANTE EL PROCESO AUTONÓMICO DE ANDALUCÍA (1980)
}

The beginning of the end of Adolfo Suárez. Press and television faced with the Andalusian autonomous process (1980)

DOI: https://dx.doi.org/10.12795/RiHC.2020.i14.16

Recibido: 23/03/2020

Aceptado: $30 / 05 / 2020$

Publicado: $15 / 06 / 2020$

Jacobo Herrero Izquierdo

ORCID (iD) 0000-0001-5672-3505

Universidad de Valladolid, España

jacoboherrizq@gmail.com

Itziar Reguero Sanz

ORCID (iD) 0000-0002-3274-1861

Universidad de Valladolid, España

itziar.reguero@uva.es

Como citar este artículo: Herrero, Jacobo, y Reguero, Itziar (2020): “El principio del fin de Adolfo Suárez. La prensa y la televisión ante el proceso autonómico de Andalucía (1980)”, en Revista Internacional de Historia de la Comunicación, (14), ISSN 2255-5129, pp. 358-383. 
Resumen: El presente artículo interpreta el debate político y mediático que se generó en 1980 a raíz del proceso autonómico en Andalucía. La metodología se basa en un análisis de contenido cualitativo de los editoriales y de los artículos de opinión que se publicaron en El País y $A B C$, junto a un examen del papel que jugó Televisión Española en el desarrollo del autogobierno en dicha región. Las conclusiones de esta investigación revelan la complejidad del caso andaluz, su protagonismo en la esfera periodística y su influencia en la crisis del Gobierno, que acusó su indefinición a la hora de abordar la cuestión

Palabras clave: Estado de las Autonomías; Andalucía; Adolfo Suárez; Transición a la democracia; UCD.

\begin{abstract}
This paper provides an interpretation of the political and media debate that took place in Andalusia regarding the process of power devolution (the "autonomous process") in 1980. The methodology is based on the qualitative analysis of the articles and editorials published in the national dailies EI País and $A B C$, combined with a review of the role played by the public broadcaster Television Española, during the abovementioned process. The conclusions of this investigation reveal the complexity of the Andalusian case, as well as the prominent media coverage it received and its influence on the crisis of the Spanish Government, at the time affected by its lack of definition in addressing this burning issue.
\end{abstract}

Keywords: State of Autonomies, Andalusia, Adolfo Suárez, Transition to democracy, UCD.

\title{
Introducción
}

\section{Justificación del tema y estado de la cuestión}

El proceso autonómico en Andalucía, al margen de los antecedentes históricos que se remontan a los años 80 del siglo XIX, a la segunda década del XX y a los infructuosos intentos planteados en la II República, eclosiona en el tránsito de la dictadura hacia la democracia, con consecuencias clave para la configuración territorial de España (Reguero Sanz, 2018). Tal y como afirmaba Sebastiá Serra, "el Estado de las Autonomías ha pasado por diferentes fases; ha sido un proceso lleno de interrogantes, de situaciones de consenso, de aproximaciones y situaciones conflictivas" (1995: 413). Y Andalucía, inmersa en ese complejo y caleidoscópico entramado, jugó un papel determinante en este sentido. 
Algunos autores, desde el jienense Antonio Checa Godoy (1980; 1982; 1991), con aportaciones imprescindibles para entender la historia del pueblo andaluz, pasando por Manuel Ruiz Romero (1998; 2003; 2005) o Rafael Quirosa-Cheyrouze y Muñoz (2006), confirman en sus obras la importancia del proceso autonómico andaluz y su papel sobresaliente en el desarrollo del Estado autonómico que se fraguó durante la Transición. También contamos con el testimonio de protagonistas que vivieron y participaron activamente en dicho proceso, como Manuel Clavero (1982; 1996; 2006), uno de los "padres" del proyecto autonómico, o Antonio Fontán (1995), ministro de Administración Territorial en UCD entre 1979 y 1980, quienes han querido destacar los rasgos y particularidades de lo ocurrido en Andalucía.

Resulta difícil, en efecto, comprender los primeros años de la democracia en España sin prestar atención a una región que condicionó, no solo el devenir del proceso territorial, sino también el futuro de un partido y de un Gobierno. El mero hecho de que José Oneto, testigo directo de la Transición, sostuviese que, con el 28 de febrero, día de la consulta autonómica andaluza, comenzaba "la auténtica destrucción de Adolfo Suárez" (Ónega, 2013: 133), plantea una hipótesis no poco trascendente y que parece consolidarse cuando se añaden líneas como las firmadas por Emilio Attard (1983) o Silvia AlonsoCastrillo quien afirma que Andalucía fue "una de las causas primordiales de la decadencia y descomposición de la UCD" (1996: 519).

Tesis como esta, entre otras, nos guían inevitablemente a la búsqueda de nuevas respuestas; a la obtención de un porqué que nos explique la magnitud del caso andaluz y su repercusión en la última legislatura presidida por el abulense. A ese respecto, la investigación que aquí se presenta pretende sumar una nueva aportación al estudio de la experiencia autonómica en Andalucía. Y lo hace a través del análisis del contenido de los diarios El País y $A B C$, y mediante el examen del papel que jugó Televisión Española a este respecto, cadena que regentaba el monopolio del mercado televisivo español.

Atender al tratamiento informativo de las diferentes voces mediáticas y a su rol como formadores y transformadores de opinión pública, resulta una tarea compleja aunque necesaria, sobre todo si tenemos en cuenta que la cuestión andaluza estuvo presente en determinados hitos clave de esta etapa, como la moción de censura contra el presidente Suárez, en mayo de 1980, o la cuestión de confianza presentada meses más tarde (septiembre 1980). De igual modo, estudiar cómo estos mass media, en situaciones sensiblemente distintas $(A B C$ y $E l$ País eran órganos de prensa independientes, mientras que la televisión pública se encontraba bajo control gubernamental), orientaron el proceso de autonomía andaluz aporta un relato ineludible, pese a que muchas veces el discurso periodístico haya pasado un tanto desapercibido en las investigaciones sobre este asunto, ya que las contribuciones son escasas y basadas en prensa regional (Checa, 1991; Ruiz, 1998; García, 2003). 


\section{Metodología}

En aras de cubrir el vacío historiográfico existente, la presente propuesta busca reivindicar la importancia de unos diarios que ejercieron como testigos y agentes históricos de primer orden, al igual que lo hizo la pequeña pantalla, de la que también se subraya su papel como motor de la Historia, y cuyo servicio informativo resultó muchas veces incómodo, en tanto que TVE era considerada el escaparate y el brazo informativo del Gobierno (García Matilla, 1996). Esto último, en esencia, justifica uno de los objetivos centrales de esta investigación, pues resultaba especialmente interesante acometer el análisis de las principales reacciones mediáticas respecto de los programas y contenidos televisivos.

En lo que se refiere a las fuentes objeto de estudio, la elección de los diarios, $A B C$ y $E I$ País, responde a las siguientes razones. La primera de ellas es la geográfica, ya que se ha centrado la atención en la prensa editada en Madrid. Si bien es cierto que todos los diarios tuvieron un papel importante en la consolidación de la democracia española, se coincide con Crespo de Lara en que los llamados periódicos nacionales fueron los principales formadores de opinión (2014: 204). La segunda razón radica en el disímil peso histórico de las cabeceras; en el análisis combinamos un diario publicado desde comienzos del siglo XX con otro que acababa de nacer en 1976.

El tercer motivo es la línea editorial: cada uno de ellos se sitúa en un punto del espectro ideológico. $A B C$ es conservador, tradicional, defensor de los valores cristianos (Berrocal y Rodríguez-Maribona, 1998: 154) y, sobre todo, monárquico (Pérez Mateos, 2002: 180), mientras que El País tenía un perfil liberal, progresista y europeísta (Zugasti, 2007: 8586). Y, por último, por razones de difusión: además de tener la mayor tirada de la capital de España (Alférez, 1986: 263 - 277), ambos periódicos eran los dos de información general que tenían un mayor número de lectores. A fin de realizar un estudio completo, el periodo analizado abarca el todo el proceso andaluz que tuvo lugar durante 1980 . Por ello, se han sometido a examen todos los editoriales y artículos de opinión publicados desde el 1 de enero hasta el 31 de octubre del citado año que abordan esta temática.

Así pues, este trabajo, basado en una metodología de análisis de contenido cualitativo, pretende dar respuesta a los siguientes interrogantes: ¿Qué estrategias y discursos plantearon El País y $A B C$ para referirse al proceso autonómico en Andalucía? ¿Qué papel cumplió TVE? ¿Qué tipo de contenidos se emitieron en el medio audiovisual en relación con dicha región y dicho proceso? ¿Cómo reaccionaron los partidos políticos a los contenidos televisivos? ¿Y la propia prensa? Partiendo de esta base, los próximos párrafos se retrotraen al origen de unos acontecimientos cruciales, muchas veces difusos, otras tantas convulsos, pero no por ello menos importantes. En el cuarenta aniversario de la conformación de Andalucía como comunidad autónoma, este artículo regresa a la génesis y al punto de partida. 


\section{Una aproximación histórica: la autonomía andaluza enmarcada en los inicios de la descentralización (1975 - 1979)}

A fin de comprender lo ocurrido en el proceso autonómico en Andalucía a lo largo de 1980, es necesario realizar una visión retrospectiva sobre lo sucedido a partir de la muerte de Franco en lo relativo a la organización territorial del Estado. La idea de que democracia y autonomía debían ir de la mano se manifestó pronto, casi en los primeros días de la Transición. Probablemente, uno de los antecedentes más tempranos se encuentra en la proclamación de Juan Carlos de Borbón como Rey de España, en noviembre de 1975. Fue entonces cuando el monarca apeló a la necesidad de construir "un orden justo, igual para todos" que permitiera reconocer, dentro de la unidad del Reino y del Estado, las peculiaridades regionales como expresión de la diversidad de pueblos que constituyen la realidad de España ${ }^{1}$.

Junto a esta clara voluntad descentralizadora manifestada por el Rey, clave por lo que representaba su figura, los primeros pasos reales para la confección del Estado autonómico arrancaron tras aprobarse la Ley para la Reforma Política, en diciembre de 1976. En aquel momento, el presidente Adolfo Suárez se dispuso a realizar un pacto con los partidos de la oposición (la llamada 'Comisión de los Nueve') y comenzó a tratarse el carácter 'multinacional y multirregional' del Estado. Ya en este primer estadio, se procedió a la diferenciación entre lo que vendrían a llamarse 'nacionalidades' con rasgos históricos propios, véase Cataluña, País Vasco y Galicia, y las demás regiones de España (Powell, 2011: 16), una terminología que más tarde acarrearía consecuencias.

Después, celebradas las primeras elecciones generales el 15 de junio de 1977, el Gobierno de UCD inició el proceso de ordenación territorial, estableciendo regímenes preautonómicos en Cataluña (septiembre 1977) y en el País Vasco (diciembre 1977). Siguió un efecto "contagio" ${ }^{2}$ que hizo que se extendieran dichos organismos por todo el territorio español mediante Decretos-Leyes. Así ocurrió en Galicia, Valencia, Aragón,

\footnotetext{
${ }^{1}$ Discurso del Rey Juan Carlos I. Disponible en: https://www.youtube.com/watch?v=1RRwRSGI79M [última consulta: 28-05-2018].

${ }^{2}$ La extensión de regímenes preautonómicos por toda España responde una triple explicación: en primer lugar, el Gobierno no quería repetir los errores cometidos en la Segunda República, concediendo regímenes de privilegio solo a ciertas regiones, lo que causaría desconfianza en las demás; a su vez, se propuso la generalización de las preautonomías para en un futuro poder equiparar los techos competenciales de cada una de ellas. Finalmente, el hecho de conceder estos organismos en Cataluña y en el País Vasco despertó en algunas regiones un sentimiento nacionalista que nunca se había manifestado ya que, si algunas contaban con preautonomías, el resto aspiraba a ello para no quedarse atrás (Pelaz, 2011: 44).
} 
Canarias, Asturias, Murcia, Extremadura, Baleares, Castilla y León, Castilla-La Mancha y Andalucía.

La propia Andalucía, pese a no haber gozado de Estatuto durante la Segunda República, manifestó contar con una marcada y sentida identidad regional. Tanto fue así que, el 4 de diciembre de 1977, salieron a la calle un millón de andaluces para manifestarse y reclamar la autonomía. Como recuerda Juan de Dios Mellado, periodista y asistente a aquella multitudinaria cita apoyada por la $U C D^{3}$, "fue ese día cuando se dijo, claro y rotundo, nuestra apuesta por la autonomía del pueblo andaluz"4.

Esta manifestación, no obstante, no discurrió por cauces pacíficos en todas las ciudades. En Málaga, único lugar en cuya Diputación no ondeaba la bandera autonómica (verdiblanca), los participantes llegaron a enfrentarse con la policía, al reprimir esta última la iniciativa de colocar la insignia en el balcón del palacio provincial. El balance fue de un muerto, un herido y varios contusionados. El asesinato de un civil, Manuel García Caparrós, provocó una virulenta respuesta por parte de las organizaciones convocantes, que llamaron a una jornada de luto de 24 horas recomendando a la ciudadanía mantenerse en sus casas de cara a evitar más incidentes (Ruiz, 2005: 48). Este hecho, en el fondo, parecía una clara advertencia de que la autonomía andaluza, desarrollada durante el proceso de Transición, no iba a ser una tarea fácil.

En todo caso, el desencadenante de buena parte del "enredo" que atravesó esta comunidad en los meses siguientes se encontraba en las disposiciones autonómicas incluidas en la Constitución de 1978. El artículo 2 establecía que el país se fundamentaba "en la indivisible unidad de la Nación española, patria común e indivisible de todos los españoles", lo que contradecía lo dispuesto en el mismo texto, que reconocía y garantizaba "el derecho a la autonomía de las nacionalidades y regiones que la integran y la solidaridad entre todas ellas". Asimismo, es importante subrayar que en ningún momento la Carta Magna explicaba a qué regiones hacía referencia el término nacionalidad. No en vano varios autores aseguran que el Título VIII, el relativo a la organización territorial del Estado, fue el más debatido por los expertos debido a la dificultad que entrañaba. Para Tusell, la fórmula a la que se llegó resultó "desafortunada, incompleta y evidentemente ambigua" (1999: 133).

\footnotetext{
${ }^{3}$ A El País le sorprendía que Unión de Centro Democrático apoyara la manifestación andaluza y gallega, y no acelerase más el ritmo de la preautonomía en Euskadi, que para el periódico se presentaba fundamental para asentar un régimen de libertades: “¿Cómo se compagina el entusiasmo autonómico de UCD, que le convierte en uno de los principales protagonistas de las jornadas de afirmación que, hoy domingo, se celebran en Andalucía y Galicia, con su vacilante e incoherente política en el País Vasco? "Las lecciones de Pamplona", El País, 04-12-1977. Editorial.
}

${ }^{4}$ Entrevista a Juan de Dios Mellado, 07-04-2017. 
De este modo, la Constitución de 1978 contempló dos vías para el ejercicio del derecho a la autonomía. Por un lado, la ordinaria, a través del artículo $143^{5}$, que regulaba un procedimiento lento y un acceso diferido, tras un plazo de cinco años, a la plenitud de competencias. Por otro, la vía rápida, recogida en el artículo $151^{6}$ y que permitía el acceso inmediato de las comunidades 'históricas' y a otras regiones que pusieran en marcha una iniciativa que había de ser ratificada en referéndum, por el voto afirmativo de la mayoría de electores en cada provincia (Calvo-Sotelo, 2011: 86). Pese a lo dispuesto, la solución ni satisfizo a todos los partidos políticos, ni estableció un modelo autonómico final. Lo que hizo fue, básicamente, presentar las condiciones para que las regiones, con el consentimiento popular, pudieran decidir el modo de acceso la autonomía (Giordano y Roller, 2004: 2167).

Fuera como fuese, el proceso continuó su curso y Cataluña y País Vasco iniciaron los trámites para redactar su Estatuto de Autonomía prácticamente de forma paralela. Ambos textos se negociaron durante el verano de 1979, primero, en el Palacio de la Moncloa y después, en la Comisión Constitucional del Congreso. Aprobados por el Parlamento, los Estatutos de Guernica y Sau fueron refrendados el 25 de octubre de 1979. Posteriormente, se promulgaron el 18 de diciembre del mismo año. Con el eco de dichos estatutos y las aspiraciones de las comunidades 'no históricas' comenzamos el repaso por el desarrollo autonómico andaluz desde la atalaya mediática.

\section{Campaña electoral: "Andaluz, este no es tu referéndum"}

El 1980 fue especialmente convulso en el panorama político español. Tras la aprobación y el refrendo de los Estatutos de Autonomía en Cataluña y País Vasco, la nueva década comenzó con polémica, y lo hizo, precisamente, en Andalucía. Esta región, que ya venía manifestando su ferviente sentimiento autonómico, comunicó su deseo por acceder a su autonomía a través de la vía rápida del 151. El Gobierno, sin embargo, trataría de impedírselo por todos los medios posibles.

\footnotetext{
${ }^{5}$ El artículo 143 de la Constitución:

http://www.congreso.es/consti/constitucion/indice/titulos/articulos.jsp?ini=143\&tipo=2 consulta: $17 / 08 / 2017]$.

${ }^{6}$ El artículo 151 de la Constitución:

http://www.congreso.es/consti/constitucion/indice/titulos/articulos.jsp?ini=151\&tipo=2 [última consulta: 17/08/2017].
} 
Este año, considerado por Powell como "el más duro en la vida política de Suárez" (2004: 168), se inició pues con la propuesta de la Junta preautonómica de Andalucía, presidida por Rafael Escuredo (miembro del Partido Socialista Obrero Español), que trasladó su deseo por tomar la vía rápida constitucional. Para ello, al no ser Andalucía una de las llamadas 'históricas', había que convocar una consulta en todas y cada una de las provincias de la futura comunidad. Y no solo eso: en todas ellas había que obtener mayoría absoluta a favor del método rápido, como rezaba la Ley de Leyes ${ }^{7}$.

Sin embargo, en un alarde de política zigzagueante, el Ejecutivo centrista decidió contemplar exclusivamente el 151 para Cataluña, País Vasco y Galicia, dejando a Andalucía fuera de la fórmula. El desencadenante del conflicto llegó el 16 de enero de 1980, cuando la comisión ejecutiva de UCD hizo pública su decisión. De la vía rápida, a la lenta. Así lo explicaba El País: "La comisión ejecutiva de UCD acuerda [...] que a partir de ahora todos los procesos autonómicos sean llevados a cabo por la vía del artículo 143 de la Constitución"8. El problema, en realidad, residía en el hecho de que Suárez, debido a las demandas andaluzas, había pactado meses antes la celebración de un referéndum previsto para el 28 de febrero (Pérez Herrera, 2017: 353) ${ }^{9}$ :

Suárez dijo 'sí a Escuredo y los hombres de UCD tuvieron que ver cómo hacer compatible ese «sí» al referéndum con el 'no' al 151 que habían adoptado como postura del Gobierno. Una vez más les tocaba reajustar el programa al ejercicio de una práctica política en la que había demasiados factores en juego (Ibidem: 354).

Así pues el Gobierno aceptó la consulta del $28-\mathrm{F}$, pero pidió la abstención en el voto ${ }^{10}$, actitud cuanto menos polémica y que pronto trajo consecuencias. Las reacciones a este hecho no se hicieron esperar y a principios del mes se produjo la salida de Manuel Clavero, quien había dirigido hasta el entonces el proceso descentralizador. Este anunció su dimisión como Ministro de Cultura por su disconformidad con el procedimiento que el comité ejecutivo de UCD acordó para Andalucía ${ }^{11}$.

Los motivos de aquella decisión, primer varapalo para el Gabinete centrista, respondían a lo que posteriormente se convertiría en uno de los principales motivos de crítica por

\footnotetext{
${ }^{7}$ Obtenido en: http://www.congreso.es/consti/constitucion/indice/sinopsis/sinopsis.jsp?art=151\&tipo=2 [última consulta: 25/10/2019]

8"UCD decide que la autonomía andaluza se lleve por la 'vía lenta'”, El País, 16-01-1980. Portada.

${ }^{9}$ Manuel Clavero fija la primera de las reuniones entre Suárez y Escuredo el 3 de octubre de 1979, el mismo día en el que Pérez-Llorca y Alfonso Guerra acordaron un posible pacto de Estado y el inicio de la racionalización del proceso. «Debió recibir Suárez buenas impresiones [...], cuando llegó al acuerdo con Rafael Escuredo de que el referéndum se celebraría el primero de marzo de 1980" (Clavero, 1983: 123).

10 “El partido del Gobierno propugna la abstención en el referéndum andaluz", El País, 17-01-1980. Portada.

11“De la Cierva sustituye a Clavero y Pérez Llorca asume las Relaciones con Las Cortes", El País, 17-011980. Portada.
} 
parte de la oposición y de ciertos sectores de la prensa: el agravio comparativo respecto a Cataluña y País Vasco. Más singularmente, los recelos y quejas producto de comparar lo previsto para Andalucía con lo ocurrido en aquellas comunidades, ya con sus respectivos Estatutos, alcanzaron rápidamente niveles importantes.

Bien es cierto, no obstante, que a mediados de enero, y aunque con reservas, El País había apuntado que la decisión que había tomado UCD en Andalucía era legítima, ya que, a juicio de esta cabecera, no era necesario utilizar el 151 para acceder a la autonomía. Pese a ello, el diario de Cebrián no dudó en señalar al Ejecutivo de Suárez como el principal responsable de la situación creada en la región andaluza. Su editorial, publicado en la segunda quincena de enero, aseguraba que "gran parte de las responsabilidades [...] incumben a los hombres y al partido que ha ejercido el poder desde las elecciones de junio de 1977" 12.

Ciertamente, en lo que concierne al referéndum andaluz, El País no mostró una postura o un posicionamiento claro, puesto que el proceso autonómico admitía motivos tanto para el respaldo como para el rechazo. Aun así, lo que sin duda apoyó este periódico desde el principio fue la igualdad de oportunidades que cada territorio merecía, con independencia de recibir el apadrinamiento del Gobierno o de la oposición. En definitiva, aplicar las mismas reglas del juego era, para la cabecera, sintomático de un buen sistema democrático.

Quizás fuera esto; el requerimiento a que existiese un cierto equilibrio en el proceso autonómico, la razón que explica que el desarrollo de la campaña electoral en Televisión Española suscitase notable controversia en las páginas de opinión y en la sección editorial del rotativo de PRISA ${ }^{13}$. Como rememoraría Eduardo Sotillos años más tarde, la televisión se había convertido en un "obsceno objeto de deseo" para todas las fuerzas (2002:158). La lucha de los diferentes partidos políticos por controlarla se había acrecentado a raíz de las elecciones de 1979, que determinaron el fin del consenso y pusieron sobre la mesa la necesidad de aplicar modos y criterios democráticos a la televisión. Como nos indica Juan Francisco Fuentes:

La consolidación de la democracia suponía precisamente un mayor protagonismo del Parlamento y de los partidos políticos $y$, paralelamente, como en un mecanismo de vasos comunicantes, un peso decreciente de los poderes

\footnotetext{
12 “Autonomías: los costes del oportunismo", El País, 17-01-1980. Editorial.

13 Para Luis Ortega (1982) hubo varias cuestiones que podrían entenderse como un trato discriminatorio de Andalucía respecto de Cataluña y País Vasco. Estas fueron: primero, la propia vía del 143 planteada por UCD; segundo, la pregunta al electorado el día de la consulta, a todas luces "retorcida y confusa"; tercero, la financiación de misma campaña (125 millones. La mitad de lo presupuestado para el referéndum vasco y catalán); cuarto, la duración de la campaña (15 días frente a los 21 que duró en Cataluña y Euskadi). Y quinto, los medios de difusión como la televisión.
} 
carismáticos, por muy avalados por las urnas que estuvieran. A más democracia, más Parlamento; a más Parlamento, menos televisión (2016: 185).

En ese sentido, el papel que desempeñó Televisión Española en la campaña para el 28F fue objeto de atención permanente, antes incluso de que comenzasen a emitirse los espacios cedidos por RTVE para la propaganda. Un ejemplo de ello es que ciertos representantes de la oposición, como el mencionado Rafael Escuredo, advirtieron y denunciaron los posibles manejos gubernamentales que podían producirse en la cadena pública los días previos a la consulta. Aquí la prueba: las palabras de Escuredo ante una posible aparición televisiva de Suárez: "Si eso ocurre, yo ya tengo preparada mi respuesta, pero, naturalmente, no voy a desvelarla ahora"14.

Estas amenazas, si pueden calificarse como tal, venían pocos días después de que el político hubiese realizado una huelga de hambre con tiempo limitado para abogar por los derechos de su región ${ }^{15}$. Aquella reivindicación fue, para El País ${ }^{16}$, motivo de burla; en primer lugar, por representar un comportamiento fuera de lógica, ya que los ciudadanos y electores merecían más respeto. En segundo término, el "ayuno" de Escuredo, como así lo definió este diario, se producía en lo que normalmente se asociaba a cuestiones más trascendentes -como la violación de los derechos humanos- y no solían tener fecha final ${ }^{17}$.

En cualquier caso, articulistas prestigiosos del "diario independiente de la mañana", según su lema, sí apoyaron a Escuredo en otras de sus reivindicaciones, como la que hizo referencia a un trato discriminatorio hacia el político por parte de la televisión. Prueba de esto último es el artículo firmado por Daniel Gavela y publicado el día 7 de febrero de 1980, donde el periodista arremetió contra "la actuación arbitraria del Gobierno" y la "ley del silencio" que pesaba en los medios informativos estatales sobre el presidente de la Junta de Andalucía" (Gavela, 1980).

\footnotetext{
14 "El agravio comparativo llevará a los andaluces a las urnas", $A B C, 13-02-1980$,

${ }^{15}$ El propio Rafael Escuredo (1980) publicó un artículo en El País relatando los motivos de su huelga de hambre: "Cuando Andalucía deja de estar de rodillas y se incorpora para exigir un lugar en el futuro que depare un orden más justo, más racional y con menos privilegios sangrantes, las viejas voces, los eternos coros antisociales, se ponen en movimiento, intentando alarmar a un pueblo que tuvo que soportar durante siglos toda clase de oprobios, vejaciones e injusticias, en beneficio y provecho de esas minorías que hoy comienzan a resucitar sus miedos y sus consignas".

${ }^{16} \mathrm{Al}$ parecer, con este tipo de acciones, lo que buscaba Escuredo era llamar la atención del electorado: "Si no había campaña, iba a haber show. Si no había dinero él iba a tener las portadas gratis. Y si no había forma de explicar la pregunta, el victimismo propiciaría que la gente acudiera a votar y que lo hiciera afirmativamente, aunque no entendiera de qué iba la cosa [...] El rostro demacrado de Rafael Escuredo es el mejor banderín de enganche para un refrendo que de otra forma, -las encuestas así lo decían- estaba perdido" (Sánchez, 2005: 99).
}

17 “El ayuno del señor Escuredo", El País, 01-02-1980. Editorial. 
Poco después, el miércoles día 13, se publicó el Real Decreto 260/1980, cuyo artículo segundo preveía la constitución del Comité de Prensa y RTVE, encargado de la concesión de espacios de propaganda. El día 20, ya formado este órgano, arrancó la emisión de espacios gratuitos en televisión, no sin que antes se produjesen nuevas protestas que señalaron las diferencias entre la campaña audiovisual desarrollada en Cataluña y País Vasco y la prevista para Andalucía.

Dado que cinco de los diez miembros que componían el Comité de Prensa y RTVE eran designados por el Gobierno, la presencia ucedista resultaba significativamente mayor que la del resto de partidos. Para mayor controversia, y ante los reproches de la oposición ${ }^{18}$, UCD se hizo con un 50\% de los tiempos concedidos por RTVE (Ortega, 1982). $\mathrm{Si}$, además, en Cataluña y Euskadi se había prestado la primera cadena de TVE para estos mensajes de propaganda, en Andalucía solo se concedió el espacio de desconexión regional del informativo Tele-Sur, que no emitía ni sábados ni domingos y que no podía llegar a ciertas zonas de Jaén y Almería.

El ya exministro centrista Manuel Clavero denunciaría esta situación mediante unas declaraciones a la Cadena $S E R$, de las que se hizo eco $A B C$ el día 19 de febrero. En ellas, el político sevillano enumeró los ejemplos de discriminación concretados en la propaganda institucional, en la publicidad facilitada a la Prensa del Estado, ambas desautorizadas en Andalucía, en el menor dinero destinado a la financiación de la campaña y, como decíamos, en el uso de la televisión: “En Andalucía sólo se permite la utilización de Tele-Sur, que no se ve en toda Andalucía. Por el contrario, en Cataluña y el País Vasco se permitió, además de la cadena regional, la utilización de la primera cadena de televisión" ${ }^{19}$.

Escasos días antes, la sección nacional de $A B C$, más concretamente la crónica de Herminio Pérez Fernández dedicada a informar sobre la actualidad parlamentaria, recogía el enfrentamiento entre el centrista Jaime García Añoveros y el vicesecretario socialista, Alfonso Guerra, quienes habían mantenido un bronco cruce de palabras en el Congreso con motivo de la gestión económica en $\operatorname{RTVE}^{20}$ y también por lo que estaba aconteciendo en Andalucía.

Guerra, haciendo uso de su turno de palabra y su retórica particular, oscilante entre la burla y la protesta, espetó en aquel pleno: “El Gobierno confunde los artículos 153 y 141 (relativos a la organización territorial del estado) con el número de millones que

\footnotetext{
18 "Protestas de la izquierda por el reparto de espacios publicitarios", El País, 21-02-1980.

19 "Incertidumbre ante el futuro escaño de Clavero", $A B C, 19-02-1980$.

${ }^{20}$ Casualmente fue el diario El País quien difundió en exclusiva los resultados de aquel informe. Publicó los datos en un serial de siete publicaciones difundidos entre el 20 y el 27 de enero de 1980. En palabras de Manuel Palacio, aquella información causó en la clase política una conmoción sin precedentes" y “convirtió a TVE en uno de los elementos medulares del conflicto político entre partidos" (2012: 230).
} 
desaparecen en Televisión" (Pérez Fernández, 1980). Llegado el 21 de febrero, con un clima de tensión que iba en aumento, la otra gran voz socialista, la de Felipe González, resaltó las dificultades que tenía la oposición para "transmitir su mensaje a la opinión pública". En el aspecto informativo, decía González, se había producido un retroceso en comparación con etapas anteriores, lo que obligaba a llevar a la calle "muchas cuestiones" (Sebastián, 1980).

Incesante el PSOE, llegaría tres días más tarde una nueva protesta de Escuredo que, sumándose al reto del mencionado Guerra y su propuesta a Arias Salgado para mantener un debate de campaña retransmitido por televisión, ofrecía su dimisión a cambio de que Suárez debatiese con él en "TVE, en el primer canal y a hora de máxima audiencia". En palabras del presidente de la Junta: "A ver si se entera de una vez el señor presidente del Gobierno de que yo también soy parte del Estado" (Castro, 1980).

Los días previos a la votación popular resultaron absolutamente frenéticos. Carrillo, en un mitin en Granada, tildó de "pillos" a los hombres de UCD e ironizó con la postura de Clavero: "Los comunistas teníamos un Ministro en el Gobierno y no lo sabíamos". En Jaén, Landelino Lavilla defendía la tesis centrista del 143; Guerra hablaba de la “derechización de UCD" y el propio Clavero, en Córdoba, era recibido a gritos de "viva Andalucía, viva autonomía". ${ }^{21}$ Todo ello, recogido en las crónicas periodísticas de dos diarios pegados a la actualidad andaluza.

El colofón final, que supondría el total descrédito del Gobierno, fue que Unión de Centro Democrático promovió la abstención con el lema: "Andaluz, este no es tu referéndum"22. El hecho fue duramente criticado por El País, tal y como vemos en estas piezas periodísticas: "El poder ejecutivo ha comenzado a pisotear con insólito descaro esas reglas mínimas de decoro, neutralidad y juego limpio que deben presidir cualquier consulta electoral"23; "en Andalucía el poder está cargando los dados para que fuera su jugada la ganadora"24.

En la misma línea, $A B C$ aseguraba que los errores cometidos habían sido de tal magnitud "que marcaban un hito en la historia española". Asimismo, el rotativo instaba a UCD a que explicase a los andaluces qué les reportaría el artículo 143 y, en definitiva, a que arreglase la mala situación que estaba polarizando -una vez más- a la sociedad española: "El presidente de «todos los andaluces» no ha sabido estar a la altura que

\footnotetext{
21 "Felipe González y Alfonso Guerra atacaron al Gobierno con dureza en diversos mítines", $A B C$, 26-021980.

${ }^{22}$ El díptico publicitario que realizó UCD se redactó en negativo y en él se reflejaba el eslogan adoptado por el partido de Suárez: "Este no es tu referéndum. Si vas a votar, vota en blanco" (Quirosa-Cheyrouze, 2006: 193).

23 “Clavero, en el camino de Damasco", El País, 19-02-1980. Editorial.

24 “¿Referéndum o jeroglífico?”, El País, 30-01-1980. Editorial.
} 
merece Andalucía, vamos a ver si UCD está dispuesta a evitar que esta región se convierta en tierra de nadie, en campo propicio para la demagogia" 25 .

En el único editorial del diario decano publicado durante la campaña electoral, este cargó igualmente contra Escuredo, a quien le enumeraba todos los errores que había cometido durante las últimas semanas: ser partidario de una de las dos opciones del referéndum, promover un irresponsable enfrentamiento entre los españoles, hacer graves acusaciones contra el Gobierno, utilizar un lenguaje impropio de quien ocupa un alto puesto político, poner en entredicho el resultado final de la consulta y opinar gratuitamente sobre el comportamiento de los electores de UCD.

Las opiniones que vertía este artículo editorial se asemejaron mucho a las pronunciadas por Pedro. J. Ramírez en su columna del día 24. Artículo que, bajo el título de "Andalucía: todos culpables" azuzó a un bando y a otro acusando a todos los partidos de "patinazos", "osadías", "frivolidades", "mal gusto" y torpezas", que no hacían sino dibujar un "enorme clima de crispación". Sobre la tele, decía lo siguiente:

La programación regional de televisión es cosa distinta de la programación nacional de televisión. Es una lástima que estos extremos hayan quedado regulados dé forma insatisfactoria para quienes propugnan el «sí», pues se les otorga un buen cúmulo de pretextos para justificar unos previsibles resultados que difícilmente se habrían visto alterados de existir mayor magnanimidad (Ramírez, 1980).

Visto el marco en que se desarrollaron los acontecimientos, solo restaba ver el desenlace final y si Escuredo, pese a recordar insistentemente su "veto" en TVE, había logrado o no su propósito de movilizar a la sociedad andaluza. A este respecto, El País pensaba que, fuera cual fuese el resultado, la votación no alteraría el curso político establecido, pues solo un ingenuo podía creer que "el presidente Suárez se sentiría obligado a presentar la dimisión ante un eventual revés, por importante que fuera, en la consulta andaluza".

Por el contrario, Felipe González señalaba que "una victoria desahogada de los "síes" en la mayoría de las provincias significaría un descalabro para el Gobierno" 26, pronóstico nada desacertado, por mucho que El País recordase el miércoles 27 la desfachatez del Ejecutivo al poner en "situación de somnolencia a su propio aparato" (RTVE) y boicotear con ello "las oportunidades de los defensores de la participación afirmativa". ${ }^{27}$ Las urnas y el pueblo andaluz hablarían la mañana siguiente. Y Suárez, que hasta el último día tuvo que negar su posible aparición en pantalla, aseguraba: “No participaré en el referéndum

\footnotetext{
25 "Andalucía: UCD tiene la palabra", $A B C, 14-02-1980$. Editorial.

26 "El 'test' andaluz", El País, 24-02-1980. Editorial.

27 “El valor del voto", El País, 27-02-1980. Editorial.
} 
andaluz; ni personalmente en aquellas tierras entrañables, ni a través de la televisión" [...] "es necesario aceptar el resultado de esta consulta popular, sea cual sea". ${ }^{28}$

\section{28-F: "Suárez, Andalucía no es tu cortijo"29}

Los resultados del referéndum andaluz del 28 de febrero de 1980 no arreglaron la confusión existente. La participación popular fue del 64,2\%, superior a la registrada en las elecciones municipales de 1979 , y el $55,8 \%$ del censo votó afirmativamente por la vía del 151 (Checa, 1980: 258). Además, la "opción rápida" obtuvo en siete provincias mayoría absoluta -en Jaén hicieron falta impugnaciones judiciales. La excepción: Almería (42,31\%), lo cual trajo nuevos problemas al Ejecutivo ${ }^{30}$.

Los dos diarios estudiados, El País y $A B C$, de inmediato analizaron los resultados de la consulta en su sección editorial. Con la mayoría de "síes" a favor del 151, el periódico de los Luca de Tena certificaba el descalabro de UCD en Andalucía, pues el resultado de la votación representaba el segundo fracaso del Gobierno en la región.

El primero había llegado en los citados comicios municipales y, con este último, $A B C$ pedía al Gabinete que reaccionase y tuviese en cuenta los resultados: "Políticamente UCD ha sufrido un duro quebranto. [...] La Andalucía hoy perdida [...] podría haber jugado un papel de equilibrio si desde un principio se le hubiera dedicado la atención que merece". No obstante, y pese a señalar estos errores, $A B C$ entendía que las circunstancias favorecían al partido centrista, por lo que propuso a este último cumplir con las promesas iniciales. Es decir, que hiciese efectiva la autonomía plena a través del 143, de igual modo que se lograba con el 151:

UCD parece haberse dado cuenta de sus errores cuando afirma en su comunicado de ayer «que la vía del artículo 143 garantiza que al final del proceso, absolutamente todas las autonomías serán iguales». Es un reto que UCD se hace a sí misma, porque de ella depende tanto el calendario como el contenido del

\footnotetext{
28 "Hay que aceptar el resultado del referéndum", $A B C$, 27-02-1980.

${ }^{29}$ Esta frase fue extraída de Mellado (2014)

${ }^{30}$ La prensa internacional también se hizo eco de esta idea. A modo de ejemplo, se reproducen las palabras de The Guardian al conocerse los resultados en Andalucía: "Premier Adolfo Suárez and his UCD Government have been shocked by the result of the Andalucian Autonomy referendum which were announced early yesterday". "Suárez shocked by autonomy vote", The Guardian, 01-03-1980, p. 5.
} 
futuro Estatuto. Haciendo realidad estos propósitos, enfrentándose a la izquierda con imaginación, es como UCD podría volver a contar con los votos andaluces ${ }^{31}$.

Por otra parte, El País no cesó en su empeño por señalar "el bochornoso espectáculo" causado por el referéndum andaluz y pidió a UCD responsabilidad en aras de resolver los problemas andaluces, así como los movimientos nacionalistas y regionalistas, que, el propio partido, "aprendiz de brujo, creído demoníacamente astuto e ingenuamente irresponsable", había contribuido a poner en marcha ${ }^{32}$. No obstante, el diario de Cebrián continuó en la misma línea crítica, reprochando a todas las fuerzas su mala actuación. También arremetió contra el Partido Socialista y le reprobó haber promovido la "irresponsable" vía rápida con tal de derrotar al Gobierno: "No se puede decir que los partidos de la oposición, sobre todo los socialistas, hayan actuado sin dobles intenciones [...] al apoyar denodadamente la vía del artículo 151, cuyos riesgos y dificultades sus propios defensores reconocen en conversaciones privadas" 33 .

En cuanto al tema de Televisión Española, la experiencia del 28-F había servido, según El País, para constatar la falta de independencia de la cadena pública y para retratarla como una "bomba de neutrones política" capaz de obrar un "silencio ruidoso" 34 falto de toda ejemplaridad democrática. Escuredo, una semana antes, se había pronunciado de forma similar con unas palabras que tuvieron su eco en el ejemplar de $A B C$ : "El señor Escuredo dijo: RTVE ha ofrecido resultados que se daban como fijos, de un partido. UCD no ha querido exponer los datos oficiales". ${ }^{35}$

Con lo visto, 1980 comenzaba a ponerse muy cuesta arriba para la Unión de Centro Democrático que, tras este referéndum, evidenciaba su descrédito. Además, lejos de ser un capítulo cerrado, la problemática de Andalucía se alargaría mucho más en el tiempo. Abierto el pulso, parecía que el pueblo andaluz no iba conformarse con una media derrota. Quién sabe, incluso, si con una victoria.

\section{Moción de censura: PSOE vs. UCD}

En el mes de mayo de $1980^{36}$, el Partido Socialista de Felipe González presentó por sorpresa una moción de censura contra el Ejecutivo de Adolfo Suárez. El recurso

\footnotetext{
31 "Andalucía: segundo aviso a UCD”, $A B C, 01-03-1980$. Editorial.

32 “Andalucía”, El País, 01-03-1980. Editorial.

33 Ibidem.

34 “Torpezas en Andalucía”, El País, 07-03-1980. Editorial.

35 "Se demuestra una voluntad de plena autonomía", $A B C$, 29-02-1980.

${ }^{36}$ La moción de censura se debatió en el congreso entre los días 28 y 30 de mayo de 1980.
} 
socialista respondía, entre otras cuestiones, a la actuación que había tenido UCD en materia territorial. Lo demuestran las palabras del propio González en aquella sesión parlamentaria:

¿Cuáles son los problemas que tiene España? [...] La construcción del Estado de las autonomías en el mantenimiento estricto de la unidad de España y con el reforzamiento claro de la solidaridad entre los distintos pueblos que la integran [...] Sobre estos temas tiene que dar una respuesta clara el Gobierno [...] El Gobierno se ha quedado solo con su partido, que no es poco [...] En democracia es importante informar a la prensa, no intoxicarla [...] Falta en España un mensaje de esperanza $[. . .]^{37}$.

Por otro lado, la moción de censura contra Adolfo Suárez venía dada por la "intolerable situación en televisión" ${ }^{38}$, tal y como expuso un iracundo Alfonso Guerra antes de enzarzarse en el mismo debate con Rafael Arias Salgado, precisamente, a causa del despilfarro económico en RTVE:

Cuando los ciudadanos son informados de la verdad de lo que ocurre en esta cámara, los ciudadanos demuestran interés por la política. Cuando a los ciudadanos se les secuestra la realidad, los ciudadanos contestan con la apatía [...] En el debate de la semana pasada, y gracias a la retransmisión en íntegra y en directo, en radio, y la retransmisión íntegra pero en diferido, en televisión, los españoles, un gran número de españoles, vieron cómo el señor Suárez, hasta ese momento, dentro de las filas que le apoyaban, constituido como un líder carismático, caía de la vitrina y, desde el punto de vista político, se hacía pedazos en el suelo ${ }^{39}$.

La afirmación de Guerra, en efecto, se remontaba a febrero de 1980 y a la campaña electoral de la consulta autonómica en Andalucía, induciendo que, incluso varias semanas después, seguían sonando con fuerza los ecos de un polémico servicio prestado por la televisión. Protestas como las de los propios trabajadores del centro regional de TVE en Andalucía no ayudaron a la mejora, si acaso, enturbiaron más el panorama:

El personal del centro regional en Andalucía de Televisión Española está en desacuerdo con el tratamiento dado por TVE al referéndum andaluz, aunque no hará pública una nota que se había redactado, por miedo a posibles represalias. El

\footnotetext{
37 “Felipe González (PSOE) - Moción de censura a Adolfo Suárez (1980)”, ESnoticia, 12-06-2017. [Archivo de vídeo]. Recuperado de: https://www.youtube.com/watch?v=b-Szb5HobAU [última consulta 27/11/2018].

38 "Texto de la moción de censura del PSOE”, El País, 22-05-1980.

39 "Moción de censura a Adolfo Suárez (1980)", RTVE, 17-03-2020. Recuperado de: https://www.rtve.es/alacarta/videos/fue-noticia-en-el-archivo-de-rtve/mocion-censura-adolfo-suarez1980/2343639/
} 
escrito, que no verá la luz pública y al que tuvo acceso El País, fue [...] firmado por todo el personal del citado centro, excepto el director, Francisco Narbona, y la redactora María Francisca Ruiz, señora del director ${ }^{40}$.

De cualquier modo, el pleno de la moción de censura, retransmitido íntegro y en diferido por la segunda cadena de TVE, se presentó para los diferentes grupos parlamentarios como una excelente oportunidad de cara a realizar sus reivindicaciones ante la masa ingente de telespectadores. A pesar de que el mencionado González asegurase que la acción de su partido no tenía como objetivo plantear una "exhibición televisiva", ${ }^{41}$ muchos eran los que temían que las sesiones previstas para la moción se convirtieran en un show político y en un espectáculo ante los focos y las cámaras del hemiciclo: "El PSOE ha planteado la moción de censura [...] para originar un golpe de efecto con varios objetivos inmediatos. El primero de ellos, adquirir protagonismo. El segundo [...] mantener ese protagonismo de cara a la opinión pública, aprovechando la gran cobertura de medios de comunicación" (Núñez, 1980).

Partiendo de esta base, el discurso de los andalucistas del PSA liderado por Alejandro Rojas Marcos se articuló, como era de esperar, en torno a la cuestión autonómica. El programa de televisión Parlamento, presentado por Manuel Almendros, y emitido el sábado 31 de mayo a las 14:00 horas, desgranaba así los puntos centrales de la ponencia del líder del Partido Socialista Andaluz:

Abrió el turno el representante del grupo andalucista, Rojas Marcos, quien centró su intervención en criticar en profundidad las insuficiencias del proyecto autonómico que se está desarrollando en España, singularmente, con lo que considera el líder andaluz: una discriminación para Andalucía, cuyo techo autonómico a través del artículo 151 ha sido frustrado, a su juicio, por la vigente ley del referéndum, aunque, desde su punto de vista, la voluntad autonómica como nacionalidad de los andaluces está clara ${ }^{42}$.

Aunque las pretensiones andalucistas se colaban de este modo en el debate más importante de la legislatura ${ }^{43}$, no era la primera vez que la postura mayoritaria de la región se escuchaba a través de un pleno televisado. Apenas una semana antes, en la

\footnotetext{
40 "Descontento en el centro andaluz de TVE", El País, 01-03-1980.

41 "Los socialistas presentan una moción de censura a Suárez y proponen a Felipe González para presidente", El País, 22-05-1980.

42 "Moción de censura a Adolfo Suárez (1980)", RTVE, 17-03-2020. Recuperado de: https://www.rtve.es/alacarta/videos/fue-noticia-en-el-archivo-de-rtve/mocion-censura-adolfo-suarez1980/2343639/

43 Según los datos del Centro de Investigaciones Sociológicas (CIS): el seguimiento del debate fue "masivo" y sin precedentes. Un 79 por 100 de la población siguió el pleno de la moción a través de la pequeña pantalla (Centro de Investigaciones Sociológicas. "Sondeo de opinión sobre el debate de investidura de D. Felipe González". Reis, (20), 82, 195-251.
} 
sesión celebrada entre los días 20 y 21, con igual presencia de las cámaras de TVE, Manuel Clavero aludió a la "herida sangrante" ${ }^{4}$ de Andalucía, que no había podido consolidar legalmente su triunfo por culpa de que Almería, única provincia que no había alcanzado el porcentaje de votos necesario, no había visionado el programa Tele-Sur, donde se emitieron los espacios de propaganda.

Estaba claro, al menos a juicio de Clavero, que a las cortapisas gubernamentales, a la rocambolesca y confusa pregunta del día de la consulta, a la reducción de tiempos de campaña, al antiético lema encabezado por UCD y al "no es tu referéndum", había que sumar, para más inri, la labor informativa de una televisión a la que se culpaba directamente del resultado. La moción presentada por el PSOE no saldría adelante, con 166 votos en contra, 152 favorables y 21 abstenciones. Sin embargo, aunque no prosperase, resultó muy útil para la oposición, ya que causó un daño irreparable a la figura de Adolfo Suárez.

\section{Moción de confianza. Andalucía, por la vía rápida}

Tras este bache, apenas un mes después, el Ejecutivo se vio obligado a replantear la cuestión andaluza, circunstancia que los partidos nacionalistas y de izquierda aprovecharon para intensificar su ofensiva. En esta ocasión, dichas fuerzas manejaban un objetivo muy concreto: lograr que se modificase la Ley Orgánica de las Modalidades de Referéndum. Se buscaba repetir cuanto antes la consulta en Almería y, al mismo tiempo, abrir la vía del 151. En consecuencia, se llevaron al Congreso cuatro propuestas para cambiar la Ley, provenientes del PSOE, PCE, PSA y el Grupo Mixto, liderado por Clavero Arévalo, quien explicaba así la situación:

Tras reuniones con Rafael Escuredo, Felipe González y Alfonso Guerra, decidimos seguir luchando por el triunfo total [...] porque no era coherente que se perdiese un referéndum en el que el voto afirmativo había superado el $50 \%$ del censo en todas las provincias menos en una. Decidimos presentar separadamente proposiciones de ley en las que, en dichas circunstancias, se permitiera repetir el referéndum en la provincia en la que habiendo triunfado el voto afirmativo, este no llegase al 50\% del censo. El Partido Comunista y el entonces PSA que presidía Alejandro Rojas Marcos, hicieron otro tanto también separadamente (Clavero Arévalo, 2006: 49).

\footnotetext{
44 “Más de siete horas duró el debate parlamentario", $A B C$, 22-05-1980.
} 
El 12 de junio, el Parlamento realizó la votación y no se aprobó la modificación por tan solo un voto de diferencia: 163 frente a 162. UCD volvió a quedarse sola, pero le bastó para que la propuesta no prosperara. El Gobierno intentó entonces que se utilizara la vía del artículo 143 ampliando incluso las competencias de la Junta, pero tampoco hubo conformidad tras la votación. Pese a todo, la presión andaluza no cesaba y la situación se hacía cada vez más insostenible. Por ello, Adolfo Suárez, tras una nueva modificación de Gobierno ${ }^{45}$, decidió actuar y tratar de encontrar apoyos en el resto de partidos para superar 'moralmente' la moción de censura. En la búsqueda de esos aliados, el 16 de septiembre de 1980, Suárez presentó una cuestión de confianza con un doble objetivo: poner en marcha un programa de austeridad económica y desarrollar el Estado de las Autonomías.

El líder de UCD lograría esta vez el apoyo del Congreso gracias a 168 votos a favor, 164 en contra, dos abstenciones y cuatro ausencias. UCD, Minoría Catalana, Partido Andalucista y un diputado del Grupo Mixto fueron los que apoyaron el proyecto del líder centrista. Pero, ¿qué había hecho el presidente para conseguir el apoyo de catalanes y, sobre todo, de los andaluces? ${ }^{46}$. En la primera sesión, Suárez dio la sorpresa: UCD propuso reconducir la autonomía andaluza por un procedimiento equiparable a los utilizados en los estatutos vasco y catalán ${ }^{47}$. Rojas Marcos, ante las cámaras de televisión, concedía una entrevista tras el discurso del presidente donde el representante del grupo andalucista señalaba "las cosas muy positivas" y la "referencia expresa a Andalucía" en el discurso del Presidente. Acto seguido, matizaba: "Hay lagunas importantes, tan importantes que, si tuviésemos que votar ahora, votaríamos no. Ahora bien, si se resuelven esas lagunas, veremos qué pasa"48.

La cabeza más visible del PSA condicionaba así su voto a que a se devolviese a Andalucía su 28 de febrero. Y la jugada le salió bien, pues tras rechazarse una primera intentona negociada entre UCD y PSA para desviar la autonomía por la vía del 144 -denegada a su vez por la oposición al tratarse de una fórmula legal compleja- se optó finalmente por la opción del 151. Los diarios, que habían seguido al detalle el proceso de negociación, reaccionaron con alegría y sorpresa a partes iguales, aunque también aprovecharon para criticar al Gobierno por el desenlace del asunto.

\footnotetext{
${ }^{45}$ En el nuevo Ejecutivo de Adolfo Suárez estaban representadas todas las tendencias de Unión de Centro Democrático. "La crisis de Gobierno se cierra con la sustitución de Marcelino Oreja por Pérez-Llorca”, El País, 09-09-1980.

${ }^{46}$ Como señalaba Clavero Arévalo, "Andalucía se había convertido en el gran tema parlamentario tanto en la moción de censura que Felipe González presentó contra el Gobierno [...] como en la cuestión de confianza que el Gobierno presentó en el mes de septiembre" (2006: 50).

47 “El grupo andalucista votará a favor de la moción de confianza”, El País, 18-09-1980, p. 1.

48 Entrevista Rojas Marcos tras intervención Presidente Suárez Moción Confianza 1980. Recuperado de: https://www.youtube.com/watch?v=peZFH xGCTo [última consulta: 17-03-2020].
} 
La opinión de $A B C$ fue en línea directa, ya que consideraba que el Estado de las Autonomías representaba un problema clave de la política española. Es más, lo tildaba como "el más difícil de toda la política nacional, por encima del económico" ${ }^{49}$, visible en las dos grandes confrontaciones más recientes -moción de censura y cuestión de confianza-, y en la preponderancia del tema: objeto de polémica, baza decisoria en las votaciones parlamentarias e incluso motivo de acercamiento entre UCD y su gran adversario, el PSOE. Pese a calificar de "lamentable" la indefinición, los vaivenes y las improvisaciones en la construcción del Estado de las Autonomías, para este periódico, estaba fuera de toda discusión la conveniencia de resolver, cuanto antes, el entramado andaluz: "La decisión del Gobierno al proponer una solución viable, aunque sea excepcional, es acertada. No se debe someter a Andalucía a más y nuevas tensiones políticas" ${ }^{50}$.

A su vez, el diario decano defendía al Gobierno, subrayando que las autonomías, "con su lógico rosario de transferencias", estaban enmarcadas en el texto constitucional: “[...] nadie regala lo que está asignado por ley, ya que a todos interesa que el ritmo de puesta en práctica de tales responsabilidades sea el adecuado a las necesidades de quienes están dispuestos a asumirlas" 51 . Aludir al "fracaso gubernamental", añadía la cabecera, era injusto, porque la labor del Ejecutivo constituía "un intento prudente y loable de lograr aquiescencias y colaboraciones para resolver del mejor modo posible el gravísimo, y generalizado, problema autonómico" ${ }^{52}$.

Amainado el temporal, aunque de forma somera, el presidente del Gobierno, Adolfo Suárez, celebraría un encuentro con todos los medios de comunicación el 4 de octubre de 1980. Su comparecencia servía para cumplir con esa "nueva forma de gobernar" 53 prometida tras la moción de censura. Aquel encuentro se celebraba tras varios meses de silencio, de ahí que fuera especialmente relevante el orden de los temas abordados por Suárez. Ante las cámaras de TVE, el Presidente, en una rueda de prensa con estética "a la americana" ${ }^{4}$, contestó a treinta y dos preguntas durante cerca de una hora. Entre los puntos que abordó, cobró especial importancia el proceso descentralizador ${ }^{55}$, del

\footnotetext{
49 “Ante el problema autonómico", $A B C, 11-10-1980$. Editorial.

50 "El proceso autonómico andaluz", $A B C$, 27-09-1980. Editorial.

51 "La actitud catalana", $A B C, 25-09-1980$. Editorial.

52 “Ante el problema autonómico", $A B C, 11-10-1980$. Editorial.

53 "Como consecuencia del debate, Suárez anuncia un cambio de estilo de gobierno", ABC, 31-05-1980

54 "Faltó tiempo para hablar de todos los temas pendientes", $A B C, 05-10-1980$, p.1.

${ }^{55}$ Esta idea la defendió Carlos Dávila (1980) con las siguientes palabras: “Quizá el principal valor que puede derivarse de esta conferencia de prensa se pueda centrar en la definición que hizo del Estado autonómico, definición que aparece por primera vez en labios del presidente" (Dávila, 1980a).
} 
que habló largo y tendido, haciendo especial hincapié en el caso catalán, en el caso vasco $y$, también, como era lógico, en el caso andaluz ${ }^{56}$.

Con ello, quedaba patente que Andalucía y su aspiración autonómica se había "colado" entre las cuestiones de mayor urgencia de la legislatura. Lo había estado siempre, pero ahora encabezaba el discurso presidencial. No extraña, por tanto, que $A B C$ señalase que el jefe del Ejecutivo hubiese pasado "de puntillas" (Dávila, 1980a), por el resto de problemas que acosaban al país, dejando en el aire cuestiones como la incorporación de España a la OTAN o al Mercado Común Europeo, por ejemplo. Andalucía debía ir antes, y así fue, lo que otorgaba a esta región un papel sobresaliente en la agenda gubernamental. En contraste con lo que había ocurrido unos meses antes recordemos: "Andaluz, este no es tu referéndum", por extensión, tampoco es tu televisión-, la situación había dado un giro de 180 grados. La respuesta a los andaluces llegaría tres semanas más tarde, en concreto, el 22 de octubre. Después de ocho meses de enfrentamientos, de negociaciones, de tiras y aflojas, y de continuas idas y venidas, el desbloqueo se materializó en un acuerdo entre UCD y PSOE, que concedía la autonomía andaluza a través de la vía del 151.

El País se dispuso entonces a afirmar que "el sentido común y el sentido de Estado" había hecho posible que se hubiera optado por el artículo 151", aseveración que plasmó, sorprendentemente, restando crítica al Gobierno y repartiendo responsabilidades: "La solución adoptada ayer para Andalucía por todas las fuerzas políticas con representación parlamentaria ofrece una fórmula política de desbloqueo que saca el tema andaluz del callejón sin salida al que también entre todos le habían conducido". Por último, manifestaba que el único riesgo que conllevaba el acuerdo era que bordeaba la Constitución, siendo esto motivo de desagravio para aquellas personas que creían fundamental el cumplimiento de las leyes para garantizar la democracia: "La solución adoptada, políticamente útil, puede rozar razonablemente los escrúpulos de quienes piensan que en el sistema democrático el respeto a las leyes es esencial”57. Salvedad del apunte, y por fin, concluía el enredo.

Con más o menos matices, lo que resulta evidente es que la magnitud del caso andaluz determinó, desde ese instante, el proceso de construcción del Estado autonómico, (Romero, 2012: 17). Además, no ha de olvidarse su repercusión en la crisis de gobierno, que fue haciendo mella sobre Suárez y su Ejecutivo hasta el punto de hundirlo por

\footnotetext{
${ }^{56}$ Recogemos, a continuación, las declaraciones más importantes del Presidente: "El Gobierno defiende el artículo 151 para Andalucía”; "[...] estamos firmemente decididos a potenciar la creación de las Policías Autónomas y, como establece el propio artículo 17 del Estatuto de Autonomía del País Vasco, a que se comience ya la formación de miqueletes y miñones en las respectivas provincias [...]"; "A mí me parece que el hecho de que unas minorías hayan votado la cuestión de confianza no puede traer como consecuencia lógica la pretensión de que estemos potenciando la existencia de minorías regionales. Existen, ahí están, y tienen perfecto derecho a existir y a estar" (Dávila, 1980b: 6).
}

57 “Andalucía ante su autonomía”, El País, 23-10-1980. Editorial. 
completo. Rescatando las palabras de Alfonso Guerra, pronunciadas en la moción de censura: "Adolfo Suárez había caído de las vitrinas al suelo para hacerse pedazos". Y en esto, Andalucía tuvo gran parte de culpa.

\section{Conclusiones}

El desarrollo del autogobierno andaluz durante 1980 supuso el principio del fin de Adolfo Suárez y, paralelamente, de la Unión de Centro Democrático. Desde la llegada de la democracia, la región andaluza había planteado su apuesta por 'no ser una más' y conseguir las mismas competencias que las 'históricas', es decir, que Cataluña, Galicia y País Vasco. Sus pretensiones se lograron durante aquel año, de alguna forma, al adquirir un lugar privilegiado en la agenda de los medios de comunicación, así como en los debates de la Cámara Baja.

La campaña electoral del referéndum (28-F) estuvo plagada de anécdotas y dificultades; había una gran confusión, ya que era la primera (y sería la única) región 'no histórica' que trataba de acceder a la autonomía por la vía rápida y ese clima de incertidumbre se hizo notar en los diarios de la época. El País fue el que más importancia dio a esta cuestión, publicando ocho editoriales antes de la consulta, contrariamente a $A B C$, que solo editó uno. En cuanto a la argumentación esgrimida por cada uno de los diarios, cabe destacar que el joven diario dirigido por Juan Luis Cebrián apoyaba las demandas andaluzas y sostenía que esta región tenía derecho a pedir aquello que tuvieran las demás. El periódico decano obvió el tema, para no colocar a Suárez contra las cuerdas. En materia televisiva también hubo más piezas editoriales de la joven cabecera, posiblemente por su proximidad ideológica con el PSOE, quien aprovechó este referéndum para desgastar a su rival directo. En cualquier caso, la sensación en ambos diarios era que se habían producido irregularidades en el tratamiento informativo de Televisión Española, protagonista en muchas de las informaciones periodísticas.

El referéndum no resolvió el embrollo, ya que en todas las provincias tenía que haber mayoría de 'síes' y no fue así. Esta fue una dura derrota moral para el Ejecutivo de Suárez (Hopkin, 1999: 185) que había puesto todos sus esfuerzos en que el 28-F no prosperase. Las dos cabeceras analizadas resaltaron el descalabro que suponían estos resultados para la UCD, consecuencia de no haber prestado a esta comunidad autónoma la atención que merecía. Además, El País siguió minando al Ejecutivo ucedista debido a su actuación al mando de la pequeña pantalla durante el referéndum, que había evidenciado su intervención absoluta en TVE. No obstante, se considera que negar la utilización de la televisión pública a los andaluces en el 28-F generó el efecto contrario, ya que la participación en Andalucía fue superior que en los refrendos de País Vasco, Cataluña y Galicia. Y es que no había duda de que a los políticos les interesaba salir en 
televisión. El hecho de que tanto Alfonso Guerra como Rafael Escuredo (este último ofreciendo su dimisión) retasen a los hombres de UCD a mantener un debate en directo por televisión ejemplificaba la 'fiebre política televisiva' de aquel tiempo. Otros actos, como la huelga de hambre del propio Escuredo, en esencia, también querían causar un golpe de efecto y llamar la atención de los medios, en concreto, de la televisión ${ }^{58}$.

El desarrollo del Estado autonómico y el control de la televisión pública fueron piedras angulares en la moción de censura que presentó el PSOE contra el Ejecutivo de UCD. Pese a todo, no prosperó. Meses después, el Presidente quiso contar con la confianza de la Cámara y fue precisamente ahí donde volvió a cobrar interés el proceso andaluz. En la primera sesión parlamentaria, Adolfo Suárez propuso reconducir dicha autonomía por un procedimiento equiparable a los utilizados en Cataluña y País Vasco. La consecuencia de esta sorprendente medida fue inmediata: el Gobierno consiguió el apoyo de la mayoría del Congreso con los votos, entre otros, del Partido Andalucista, que cavó su tumba política con esta decisión. En aquel momento, parece que El País y $A B C$ se pusieron del lado del Gobierno y respaldaron su decisión aunque, posiblemente, ya era demasiado tarde.

En definitiva, parece que no hubo una solución que satisficiera a las 'históricas' y a las demás regiones, por lo que este proceso se fue resolviendo sobre la marcha. Ciertamente, el desarrollo del autogobierno andaluz aglutinó todas las contradicciones, indecisiones y limitaciones de todo el proceso, y demostró que se podía interpretar el marco constitucional de una forma tan laxa que parecía que no existiera legislación alguna. Como consecuencia, este asunto hizo que se mostrara la debilidad de los políticos en general y que la Unión de Centro Democrático cayera en su propia trampa. Todo este entramado, unido al acoso de la oposición, a las diferentes crisis en el seno de la UCD, a la mala situación de la economía, al constante ruido de sables y al terrorismo de ETA, provocó que Adolfo Suárez anunciara su dimisión el 29 de enero de 1981.

\section{Referencias bibliográficas}

ALFÉREZ, A. (1986): Cuarto poder en España: la prensa desde la Ley Fraga 1966, Barcelona, Plaza y Janés.

\footnotetext{
${ }^{58}$ Aunque no es objeto directo de nuestro análisis, a fin de resaltar la importancia de la televisión con fines políticos, es representativo que el informativo emitido por TeleSur no llegase a las dos provincias polémicas en el refrendo (donde hubo impugnaciones (Jaén) y donde no se llegó al mínimo de 'síes' (Almería).
} 
ALONSO-CASTRILLO, S. (1996): La apuesta del centro. Historia de la UCD, Madrid, Alianza Editorial.

ATTARD, E. (1983): Vida y muerte de UCD, Barcelona, Planeta.

BERROCAL GONZALO, S y RODRÍGUEZ-MARIBONA, C. (1998): Análisis básico de la prensa diaria. Manual para aprender a leer periódicos, Madrid, Universitas.

CALVO-SOTELO IBÁÑEZ-MARTÍN, L. (2011): "Leopoldo Calvo-Sotelo y el Estado de las Autonomías", en PELAZ, J.V. (dir.): El Estado y las Autonomías, Valladolid, Fundación Transición Española.

CASTRO, E. (24 de marzo de 1980): “Escuredo reta a Suárez a un debate en Televisión sobre la autonomía andaluza, El País.

CHECA GODOY, A. (1980): "El referéndum andaluz del 28 de febrero de 1980. Un análisis de sus resultados", en Revista de Estudios Regionales, n5, pp. 291-299.

--- (1982): “Una perspectiva del proceso autonómico andaluz”, en Leviatán, n9, pp. 7584.

--- (1991): Historia de la prensa andaluza, Sevilla, Fundación Blas Infante.

CLAVERO ARÉVALO, M. (1987): “Las nuevas autonomías: el caso andaluz", en Cuenta y Razón, no30, pp. 31-36.

--- (1996): “La elaboración del Título VIII constitucional de la Constitución y la situación actual del Estado de las Autonomías", en Estudios Regionales, no44, pp. 33-46.

--- (2006): "El nacimiento del Estado de las Autonomías", en FERRERO GARCÍA, Francisco: Un balance del Estado de las Autonomías, Mediterráneo Económico, pp. 39-52

CRESPO DE LARA, P. (2014): Triunfó la libertad de prensa (1977-2000). La transición sin ira del periodismo en España, Madrid, La esfera de los libros.

DÁVILA, C. (5 de octubre de 1980) a. "El Gobierno defiende el artículo 151 para Andalucía". $A B C$.

DÁVILA, C. (5 de octubre de 1980) b. "Recomendaría un Gobierno de coalición si el país fuera ingobernable". $A B C$, p. 6

ESCUREDO, R. (16 de febrero de 1980): "La alarma de los privilegiados", El País.

FONTAN, A. (1995): “Nacionalidades y regiones", en Nueva Revista de política, cultura y arte, $\mathrm{n} \div 41$, pp. 49-61. 
GARCÍA GORDILLO, Mạ del M. (2003): “El Día de Andalucía y el referéndum autonómico. La prensa regional como referente", en VV.AA.: Andalucía como ámbito de interés periodístico, Sevilla, Padilla Libros, pp. 95-122.

GARCÍA MATILLA, E. (1996). “Televisión española 1975-1982: los cambios antes del cambio", en Archivos de la Filmoteca, (n-23 y 24), 94-105.

GAVELA, D. (7 de febrero de 1980): "Referéndum andaluz: de la razón del Estado a la sinrazón", El País.

GIORDANO, B. \& ROLLER, E. (2004): “'Té para todos'? A comparison of the processes of devolution in Spain and the UK", en Environment and Planning, no36, pp. 21632181.

HOPKIN, J. (1999): El partido de la transición. Ascenso y Caída de la UCD, Madrid, Acento editorial.

QUIROSA-CHEYROUZE MUÑOZ, R. (2006): “UCD y el referéndum autonómico de Andalucía", en MATEOS LÓPEZ, A. y HERRERÍN LÓPEZ, Á: La España del presente: de la dictadura a la democracia, Madrid, Asociación de Historiadores del Presente, pp. 177-198.

MELLADO, J. (22 de marzo de 2014). "Suárez, icuidado con Andalucía!", La opinión de Málaga.

NÚÑEZ PÉREZ, M. (25 de mayo de 1980). “La moción de censura y la sombra de 1983”, El País.

ORTEGA ÁLVAREZ, L. (1982): "La inconstitucionalidad de la reforma de la Ley Orgánica del Referéndum". Revista Administración Pública, (97), pp. 113-122.

PELAZ, J.V. (eds). (2011): El Estado y las Autonomías, Valladolid, Fundación Transición Española.

PÉREZ FERNÁNDEZ, H. (15 de febrero de 1980): “Televisión, orden público y Andalucía provocaron la polémica", $A B C$.

PÉREZ HERRERA, G. (2017): La trayectoria política de José Pedro Pérez Llorca, Tesis Doctoral, Universidad de Navarra.

PÉREZ MATEOS, J. A. (2002): ABC, cien años de un "vicio nacional". Historia íntima del diario, Madrid, Hobby Club.

POWELL, C. (2004): "Adolfo Suárez. El presidente que se hizo a sí mismo", en BONIN, P. y POWELL, C: Adolfo Suárez, Barcelona, Ediciones B.

--- (2001): España en democracia (1975-2000), Madrid, Plaza y Janés. 
RAMÍREZ, P.J. (24 de febrero de 1980): “Andalucía: todos culpables”, $A B C$.

REGUERO SANZ, I. (2018): La otra Transición: la prensa de Madrid ante el Estado de las Autonomías (1977-1983), Tesis Doctoral, Universidad de Valladolid.

ROMERO, J. (2012): “España inacabada. Organización territorial del Estado, autonomía política y reconocimiento de la diversidad nacional", en Documents d'Anàlisi Geogràfica, no58, pp. 13-49.

RUIZ ROMERO, M. (2005): La conquista del Estatuto de Autonomía para Andalucía, Sevilla, Instituto Andaluz de Administración Pública.

--- (2003): La génesis el Estatuto de Autonomía para Andalucía en el contexto de la transición política (1975-1982), Tesis Doctoral, Universidad Pablo de Olavide, Sevilla.

--- (1998): “La prensa de Andalucía durante la transición”, en Ámbitos. Revista Andaluza de Comunicación, (nำ), pp. 231-252.

SEBASTIÁN, P. (21 de febrero de 1980). "Felipe González: 'Si se gana el referéndum andaluz, el Gobierno de Suárez debe dimitir'”, El País.

SERRA, S. (1995): "Los conflictos de competencias en el Estado de las Autonomías", en TUSELL, J., MARÍN, J. M y MATEOS, A: Historia de la transición y consolidación democrática en España, Madrid, UNED

TUSELL, J. (1999): Historia de España en el siglo XX. La transición democrática y el Gobierno Socialista, Madrid, Taurus de Bolsillo.

ZUGASTI, R. (2007): La forja de una complicidad. Monarquía y prensa en la Transición española (1975-1978), Madrid, Fragua. 